Imalat Teknolojileri ve Uygulamalart

Cilt: 2, No: 3, 2021 (10-19)

Araştırma Makalesi

e-ISSN: 2717-7475
Manufacturing Technologies and Applications

Vol: 2, Issue: 3, 2021 (10-19)

Research Article

e-ISSN: $2717-7475$

\title{
Al-NiAl Kompozitlerin Korozyon Davranışlarının İncelenmesi
}

\author{
Hüseyin DEMIRTAŞ ${ }^{1}$ iD, Ramazan YILDIZ $^{2}$ iD, Engin ÇEVIK ${ }^{2 *}$ iD \\ ${ }^{1}$ Karabük Üniversitesi, TOBB Teknik Bilimler Meslek Yüksekokulu, Karabük, Türkiye \\ ${ }^{2}$ Karabük Üniversitesi, Mühendislik Fakültesi, Karabük, Türkiye \\ ${ }^{3}$ Karabük Üniversitesi, Mühendislik Fakültesi, Karabük, Türkiye
}

\section{MAKALE BILGISII}

Alınma: 31.10 .2021

Kabul: 22.11.2021

Anahtar Kelimeler:

Aluminyum

NiAl partikül

Korozyon

\section{ÖZET}

$\mathrm{Bu}$ çalışmada saf $\mathrm{Al}$ matrise hacimce $\% 40$ oranında farklı tane boyutlarına sahip NiAl partikül ilavesinin, üretilen kompozitlerin korozyon performansına etkisini incelemek amaçlanmaktadır. Takviye malzemesi olarak kullanılan NiAl partiküller ark ergitme yöntemi ile atomca 1:1 oranında üretilip mekanik öğütme yöntemi ile ince partiküller haline getirilmiştir. Sonrasında titreşimli elek ile farklı boyutlarda sınıflandırılarak kompozit üretiminde kullanılmıştır. Böylece partikül boyutunun üretilen kompozitlerin korozif özelliklerine etkisi incelenmiştir. Takviye partikül oranını yüksek tutmak ve homojen dağılım sağlamak için basınçlı infiltrasyon yöntemi ile üretim tercih edilmiştir. Kompozitlerin korozif özellikleri \% $3.5 \mathrm{NaCl}$ ortamında potansiyodinamik polarizasyon ve daldırma korozyon testi uygulanarak belirlenmiştir. Elde edilen veriler değerlendirildiğinde 7. günde her üç numunedeki korozyon oranları birbirine yakın seyretmiştir. 21. günde ise korozyon oranı tane boyutu 45 - $63 \mu \mathrm{m}$ olan A numunesinde $0.001 \mathrm{~mm} / \mathrm{y}$ ll ölçülürken tane boyutu 90 $125 \mu \mathrm{m}$ olan $\mathrm{C}$ numunesinde $0.0075 \mathrm{~mm} /$ yıl olarak ölçülmüştür. Her iki deney metodunda da tane boyutu düştükçe korozyon dayanımının arttığ 1 gözlenmiştir.

\section{Investigation of Corrosion Behaviors of Al-NiAl Composites}

\section{ARTICLE INFO}

Received: 31.10 .2021

Accepted: 22.11 .2021

\section{Keywords:}

Aluminium

NiAl particle

Corrosion

\begin{abstract}
This study aims to investigate the effect of the addition of $40 \%$ by volume $\mathrm{NiAl}$ particles with different grain sizes to the pure $\mathrm{Al}$ matrix on the corrosion performance of the produced composites. NiAl particles used as reinforcement material were produced by arc melting method at a ratio of $1: 1$ by atom and turned into fine particles by mechanical grinding method. Afterwards, it was classified in different sizes by vibrating sieve and used in composite production. Thus, the effect of particle size on the corrosive properties of the produced composites was investigated. Production with pressure infiltration method was preferred in order to keep the reinforcement particle ratio high and to provide homogeneous distribution. The corrosive properties of the composites were determined by applying potentiodynamic polarization and immersion corrosion test in $3.5 \% \mathrm{NaCl}$ environment. When the data obtained were evaluated, the corrosion rates in all three samples were close to each other on the 7 th day. On the $21 \mathrm{st}$ day, the corrosion rate was $0.001 \mathrm{~mm} /$ year in sample A with a grain size of 45 $63 \mu \mathrm{m}$, while it was measured as $0.0075 \mathrm{~mm}$ / year in sample C with a grain size of 90 - $125 \mu \mathrm{m}$. In both test methods, it was observed that the corrosion resistance increased as the grain size decreased.
\end{abstract}

\section{GİRİS (INTRODUCTION)}

Metal matrisli kompozitlerde bölgesel korozyon çoğunlukla matris ile takviye elemanı arasında oluşan tane sınırlarında, arayüzeyde veya dislokasyon gibi kimyasal ve fiziksel heterojenliklerin olduğu yerlerde görülmektedir. Ancak birçok araştırmacı da ilave edilen takviye elemanının ve oluşan intermetalik fazlarının meydana gelen bu lokal korozyonlara karşı bir duvar görevi görerek korozyona karşı direncin yükseldiğini söylemişlerdir [1-3]. 
Seah vd. partikül yapısında ve çeşitli miktarlardaki garnet ilavesi ile üretilen LM 13 matrisli kompozitleri $\mathrm{HCl}$ çözeltisine daldırarak oluşacak korozyon üzerindeki katkısını araştırmışlardır. \% 2 -4 - 6 oranlarında olacak şekilde garnet takviyeli kompozitler üretmişler. Bu kompozitlere ve LM 13 alaşımının döküm haline T6 1 sıl işlemi uygulayarak bu iki ürün arasında karşılaştırma yapmışlardır. Numunelerin yaşlandırma içerisinde geçirdikleri sürelerin hepsinde takviye elemanı olan garnet arttıkça ağırlık kaybının azaldığını gözlemlemişlerdir. Üretilen bu kompozitlerin korozyon dayanımlarının artmasını malzeme yüzeyinde oluşan film tabakasına ve takviye malzemesi olan garnet partiküllerinin fiziksel duvar oluşturmasına bağlı olduğunu açıklamışlardır [4].

Candan yapmış olduğu çalışmada saf alüminyum matris ile takviye malzemesi olarak (13-23-37 $\mu \mathrm{m})$ boyutlarında $\mathrm{SiC}$ partiküllerini birleştirerek AlSiC kompozit malzemeleri üretmiştir. $\mathrm{Bu}$ kompozitleri farklı kaplarda \% $3.5 \mathrm{NaCl}$ çözeltisinin içerisine daldırarak 28 gün boyunca bekletmiştir. 28. günün sonunda kompozit malzemelerin korozyon sonuçlarını incelemiştir ve çıan sonuçlarda en yüksek korozyon dayanımının $13 \mu \mathrm{m}$ tane boyutuna sahip SiC takviye malzemesinin olduğu kompozitlerde olduğunu gözlemlemiştir. Kompozit içerisindeki takviye malzemesinin partikül boyutu küçüldükçe matris ile takviye malzemesi arasında oluşan tepkimeler ile meydana gelen $\mathrm{Al}_{4} \mathrm{C}_{3}$ ve serbest halde bulunan $\mathrm{Si}$ fazının yoğunluğunun artması, oluşan bu fazların $\mathrm{SiC}$ partiküllerinin birleşme noktalarına yerleşerek korozyonun ilerlemesini engellediğini belirtmiştir [5].

Bu çalışmada yüksek miktarda (\% 40) takviye partikül içeren alüminyum matrisli kompozitlerin üretimi ve özellikleri incelenmiştir. Takviye malzemesi olarak farklı boyutlarda NiAl seçilmiştir. Böylece partikül boyutunun kompozitin üretilebilirlik ve korozif özellikleri üzerindeki etkisi incelenmiştir.

\section{MATERYAL VE YÖNTEM (MATERIAL AND METHOD)}

Kompozitler, gaz basınçlı infiltrasyon yöntemi ile üretilmiştir. Üretim preform malzemelerin hazırlanması ve infiltrasyon işlemi şeklinde iki aşamada gerçekleştirilmiştir. İlk aşamada paslanmaz çelik boru ( $7 \mathrm{~mm}$ çap, $50 \mathrm{~mm}$ boy) içerisine hacimce $\% 40$ doluluk sağlayacak şekilde NiAl intermetalik partiküller yerleştirilmiştir. Partiküllerin önüne ve ardına açık gözenekli alümina parçaları yerleştirilmiştir. Bunlardan arda kalan kısım ise silika kum ile doldurulmuştur. Hazırlanan preform malzemeye ait şematik görüntü Şekil 1' de verilmiştir.

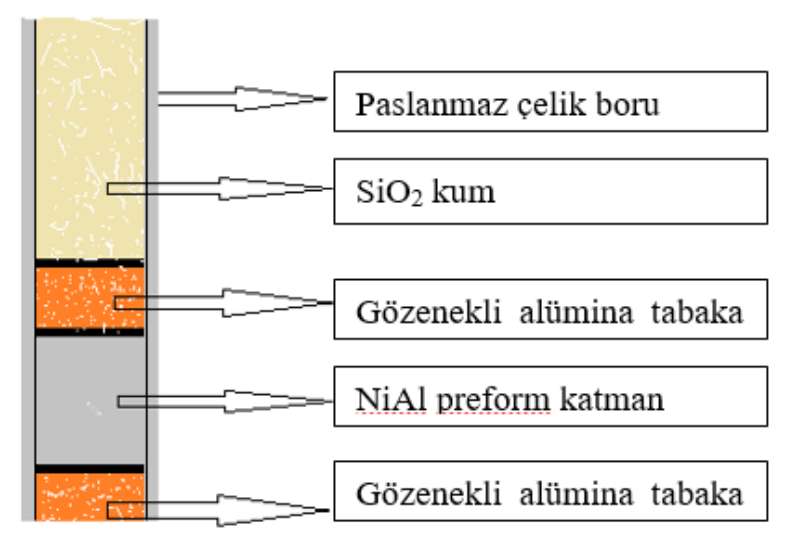

Şekil 1. Hazırlanan preform malzemenin şematik gösterimi ( Schematic representation of the preform )

Kompozit üretiminin ikinci aşamasında infilltrasyon işlemi gerçekleştirilmiştir. İnfiltrasyonun ilk aşamasında matris malzemesi $800{ }^{\circ} \mathrm{C}$ sicaklığında grafit pota içerisinde ve argon atmosferi altında sıvı faza geçene kadar tutulmuştur. Bu şekilde 1 saat bekletildikten sonra, önceden hazırlanmış olan preform malzeme infiltrasyon ünitesine yerleştirilmiş ve uygulanan 8 bar basınç ile erimiş alüminyumun preform içerisine infiltre edilmesi sağlanmıştır. İnfiltrasyon işlemi sonrası paslanmaz tüp düzenekten çıkarılmış böylece paslanmaz çelik boru içerisine yerleşmiş kompozitler elde 
edilmiştir. Sonrasında ise tornalama talaşlı imalat yöntemi ile üzerindeki paslanmaz çelik tabaka kaldırılarak kullanıma hazır kompozitler elde edilmiştir.

Öncelikle üretilen kompozit malzemeleri istenilen ölçülere getirebilmek için elmas diskli hassas kesme cihazı ile $5 \mathrm{~mm}$ yüksekliğinde kesilen kompozit numunelere Struers marka cihaz ile sicak bakalite alma işlemi gerçekleştirilmiş ve daha sonra yine Struers marka olan otomatik zımparaparlatma makinesi ile kabadan inceye olacak şekilde (240 - 1200 mesh SiC) zımparalanarak sonrasında $3 \mu \mathrm{m}$ ve $0.3 \mu \mathrm{m}$ alümina solüsyon ile parlatma işlemi yapılmıştır. Parlatılan kompozitler ultrasonik temizleme cihazında tutulduktan sonra yüzeylerine Kellar dağlama reaktifi $\left(2.5 \mathrm{ml} \mathrm{HNO}_{3}\right.$ $+1.5 \mathrm{ml} \mathrm{HCl}+1.0 \mathrm{ml} \mathrm{HF}+95 \mathrm{ml} \mathrm{su}$ ) ile dağlama işlemi yapılmıştır. Yapılan bu işlem sonrasında Nikon Epiphot 200 tipi optik mikroskop ve Carl Zeiss Ultra Plus Gemini Fesem adlı cihazda SEM görüntüleri alınmıştır.

Matris ve takviye malzemesi arasında etkileşim olup olmadığını belirlemek amacıyla Rigaku Ultra IV marka XRD cihazı ile $40 \mathrm{kv}$ jeneratör gerilimi, $30 \mathrm{~mA}$ akımda $20^{\circ}-90^{\circ}$ aralığında ve 0.02 adım tarama boyutlu 2 derece/dk hızda XRD analizleri gerçekleştirilmiştir.

Korozyon testi öncesinde aynı numuneler üzerinden yoğunluk ölçümü yapılmıştır. Yoğunluk ölçümü saf su içerisinde $0.1 \mathrm{mg}$ hassasiyetindeki Precisa XB 200 cihazında Arşimet prensibine göre yapılmıştır.

Korozyon testi ise potansiyodinamik ve daldırma korozyonu olmak üzere 2 farklı şekilde uygulanmıştır. Bu yüzden kompozit malzemeler 2 farklı boyutta kesilerek sırasıyla zımparalama, parlatma, ultrasonik cihaz ile saf su içerisinde temizleme ve sıcak hava ile kurutma işlemlerinden geçirilmiştir. Hazırlanan bu kompozit malzemelerin ilki $7 \mathrm{~mm}$ çapında ve $3 \mathrm{~mm}$ boyundadır ve bu kompozit numune PARSTAT 4000 cihazında \% $3.5 \mathrm{NaCl}$ içeren saf su çözeltisi içerisinde potansiyodinamik korozyon testlerine tabi tutulmuştur. Karşit elektrot olarak bir çift grafit çubuk ve serbest korozyon potansiyeli ölçümlerinde referans elektrot olarak doygun kalomel elektrot (SCE) kullanılmıştır. Deneyler oda sıcaklığında gerçekleştirilmiştir. Deneylerde açık devre (OC) değerini belirlemek için numunelere $-725 \mathrm{mV}, 15$ dakika süresince uygulanmıştır. Anodik ve katodik bölge deneyleri ayrık olarak yapılmıştır. Deneyler sonucunda korozyon oranı mm / yıl cinsinden ASTM G-102 standardında geçtiği şekilde Faraday kanunundan faydalanarak aşağıdaki formül ile hesaplanmıştır [6];

$$
C R=3,27 \times 10^{-3} x \frac{I_{\text {corr } x(E W)}}{d}
$$

Formülde CR korozyon oranını (mm/yıl), Icorr korozyon akım yoğunluğunu $\left(\mu \mathrm{Acm}^{2}\right)$, EW eşdeğer ağırlık (equivalent weight, gr) ve $d$ ise yoğunluğu $\left(\mathrm{gr} / \mathrm{cm}^{3}\right)$ vermektedir.

İkinci kompozit malzeme ise 21 gün sürecek daldırma korozyonu testinde kullanılmıştır. 7 mm çapında ve $3 \mathrm{~mm}$ boyunda hazırlanan kompozit malzemeler ilk olarak yüzey alanları hesaplanıp hassas terazi ile tartılmıştır. Daha sonra ise ortam sıcaklığında cam kavanozda saf su içerisine \% 3.5 $\mathrm{NaCl}$ ilavesi ile hazırlanan çözeltiye polimer file içerisine konularak daldırılmıştır. Çözelti içerisindeki kompozit malzemeler 7, 14 ve 21. günlerde bulundukları çözelti dolu kavanozlardan çıkartılıp saf su yardımı ile ultrasonik temizleyicide 5 dakika temizlendikten sonra kurutma işlemi uygulanmış ve $0.1 \mathrm{mg}$ hassasiyetteki hassas terazi ile tartılmıştır. Tartım sonucu kaydedildikten hemen sonra kompozit numuneler kavanozlara tekrar aynı şekilde daldırılmış ve bu işlem belirtilen günlerde tekrarlanmıştır. 21' inci günün sonunda aynı işlemler yapılıp tartıldıktan sonra numunelerden Nikon Epiphot 200 tipi optik mikroskop ile yüzey görüntüleri alınmıştır. Testler sonrasında ölçülen kayıp miktarları ASTM G-31'de verilen (2) nolu formül ile hesaplanmıştır [7];

$$
C R=\frac{K \times W}{A \times T \times D}
$$

Formülde CR korozyon ilerleme oranını (mm / yıl), K sabit sayıyı (mm / yıl için 87.6), W ağırlıkça kayıp miktarını (miligram), D yoğunluğu $\left(\mathrm{gr} / \mathrm{cm}^{3}\right)$, A korozyona maruz kalan yüzey alanın $\left(\mathrm{cm}^{2}\right)$ ve T ise korozyon süresini (saat) ifade etmektedir. 


\section{SONUÇLAR VE TARTIŞMA (RESULTS AND DISCUSSION)}

\subsection{Mikroyapı İncelemeleri (Microstructure Examinations)}

Takviye olarak kullanılan intermetalik NiAl (at. 1:1) ark ergitme yöntemi ile üretilmiştir. Üretim sonrası halkalı ögütücü ile yapılan ögütme işlemi sonrası titreşimli elek kullanılarak sınıflandırılan

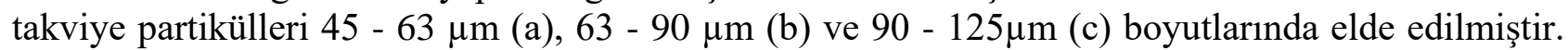
Üretimde kullanılan bu partiküllere ait SEM görüntüleri Şekil 2' de verilmiştir.

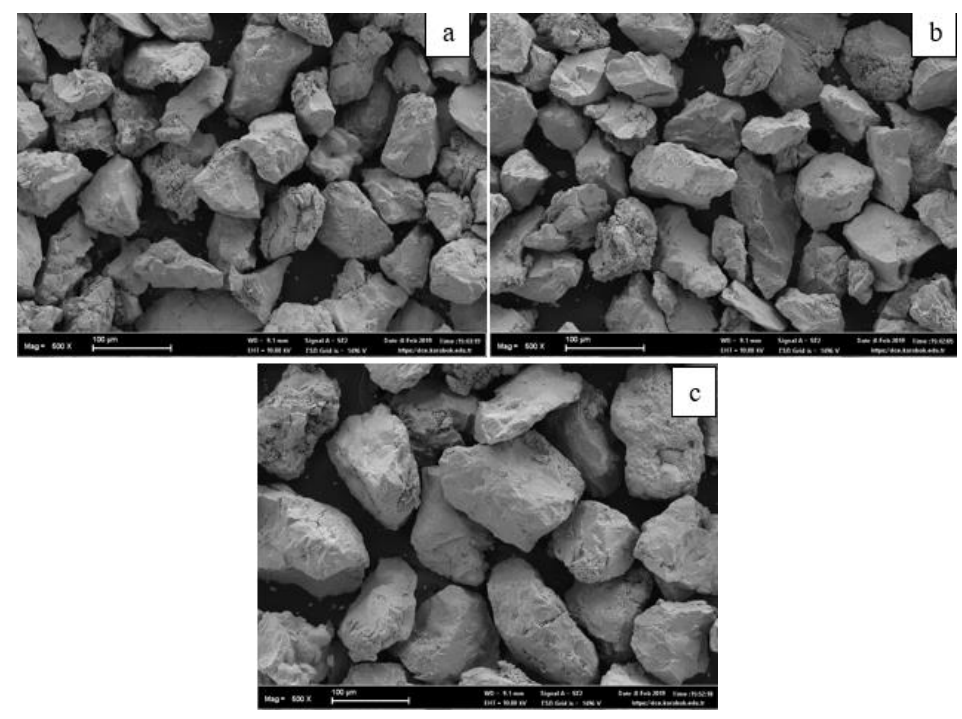

Şekil 1. Farklı boylardaki NiAl partikülleri ( Different sizes NiAl particles )

Matris malzemesi olarak ticari saflıkta alüminyum (AA1050) kullanılmıştır. Bu alüminyuma ait spektral analiz sonucu Tablo 1'de verilmiştir.

Tablo 1. Matris olarak kullanılan ticari saflıktaki alüminyumun spektral analizi (Spectral analysis of commercially pure aluminum used as matrix )

\begin{tabular}{cccccccccccc} 
& $\mathbf{P b}$ & $\mathbf{M g}$ & $\mathbf{A l}$ & $\mathbf{Z n}$ & $\mathbf{C u}$ & $\mathbf{F e}$ & $\mathbf{M n}$ & $\mathbf{N i}$ & $\mathbf{S i}$ & $\mathbf{S n}$ & $\mathbf{T i}$ \\
\hline AA1050 & 0.1 & 0.002 & 99.588 & 0.011 & 0.011 & 0.215 & --- & --- & 0.116 & --- & 0.020
\end{tabular}

Farklı boyutlarda NiAl partikül içeren Al matrisli kompozitlere ait mikroskop görüntüleri Şekil 3'te verilmiştir. Mikroyapı görüntülerinde açık renkli bölgeler $\mathrm{Al}$ matris malzemesini göstermektedir. Diğer koyu bölgeler ise partikül takviyelerine aittir. Bu bölgelerdeki kontrast farklılıkları dağlama işleminin etkisinden ve farklı fazlar içermesinden kaynaklanmaktadır. Genel olarak bakıldığında takviye malzemelerinin matris içerisinde iki boyutlu gözlemde net olmasa da üç boyutlu olarak değerlendirildiğinde homojen bir dağılım gösterdiği ve belirgin boşlukların olmadığ belirlenmiştir. $\mathrm{Bu}$ durum infiltrasyon prosesinin başarılı bir sonuç verdiğini göstermektedir. Şekil 3'deki mikroyapıda da görüldüğü üzere çeşitli renk kontrastlarında fazların varlığı aşikârdır. Bu fazların kimyasal değişimlerini belirlemek üzere fazlar üzerinden alınan EDS ölçümleri Şekil 4' te verilmiştir. $\mathrm{Bu}$ ölçüm değerleri incelendiğinde genel olarak matrisin saf $\mathrm{Al}$ ve az miktarda oksitlerden oluştuğu görülmektedir. Al' un yüksek oksijen afinitesi olduğu bilinmektedir [8]. Üretim aşamasında ise hazırlanan preform malzeme koruyucu gaz atmosferinde tutulmamıştır ve düşük miktardaki kirliliğin bu durumdan kaynaklanabileceği düşünülmektedir.

Takviye malzemesinin ise atomca yaklaşık 1:1 oranında Ni ve Al içerdiği belirlenmiştir. Fakat bu fazın yer yer üzerinde ve yanında farklı bir faz oluştuğu tespit edilmiştir. Tespit edilen bu faz üzerinde yapılan EDS ölçümünde ağırlıkça farklı oranlarda Al, Ni ve Mo elementlerini içerdiği 
görülmüştür. Bu konuda daha detaylı inceleme XRD analizlerinde yapılmış ve bu fazın üçlü Al-NiMo fazı olduğu belirlenmiştir.

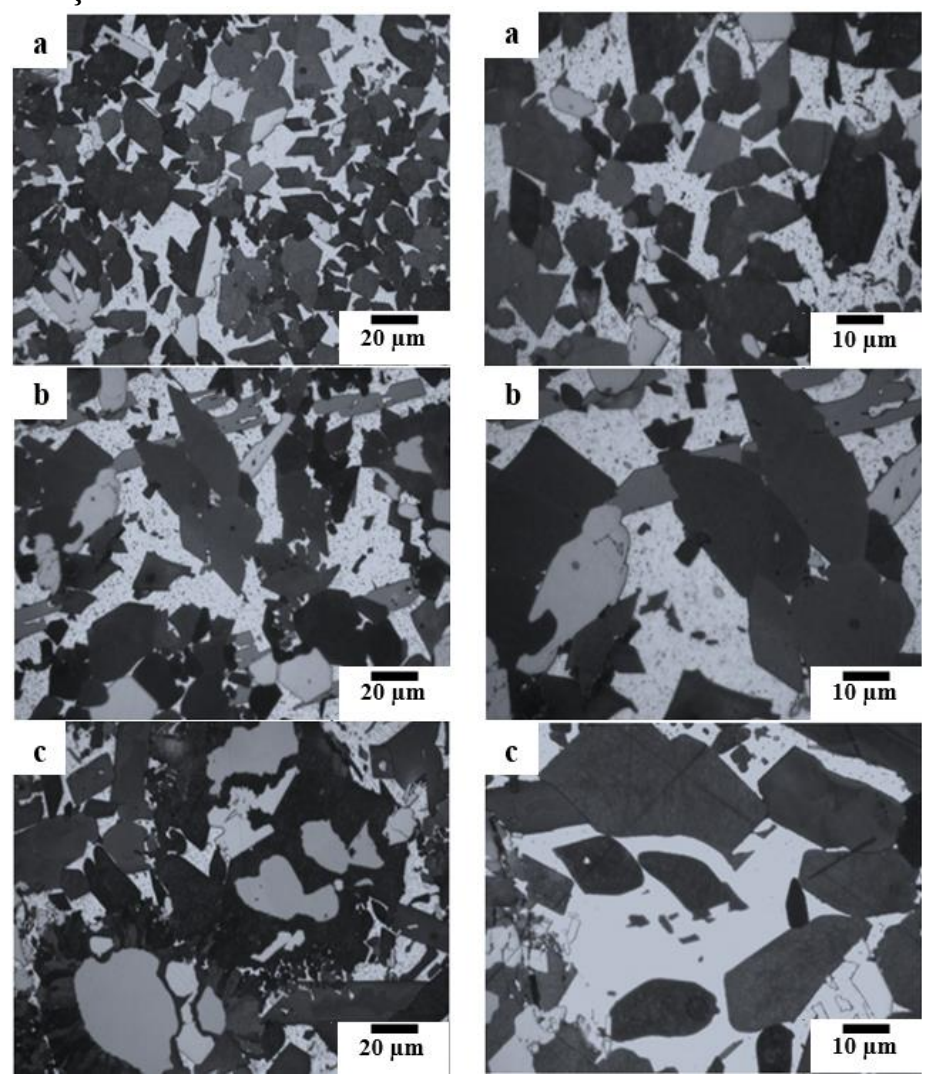

Şekil 3. Farklı boyutlarda NiAl partikül içeren kompozitlere ait mikroyapı görüntüleri ( Microstructure images of composites containing different sizes.NiAl particles )

Oluşan fazlar dışında NiAl partiküllerde büyük miktarda bozulmalar tespit edilmemiştir. Normalde NiAl' un, Al ile etkileşime geçme potansiyeli yüksektir ve böylece NiAl ile Al arasında $\mathrm{Al}$ ' ca zengin çeşitli NiAl fazlarının oluşması muhtemeldir $\left(\mathrm{Al}_{3} \mathrm{Ni}_{2}, \mathrm{Al}_{5} \mathrm{Ni}_{3}\right.$ gibi). Bu sebeple partiküllere bir miktar Mo ilave edilmiş ve üretim prosesi kısa tutulmaya çalışılmıştır. Yapılan incelemeler sonucunda alınan bu tedbirlerin faydalı olduğu görülmüştür. Fakat yine de mikroyapıda Al' ca zengin NiAl fazlarının oluştuğu XRD analizlerinde tespit edilmiştir.

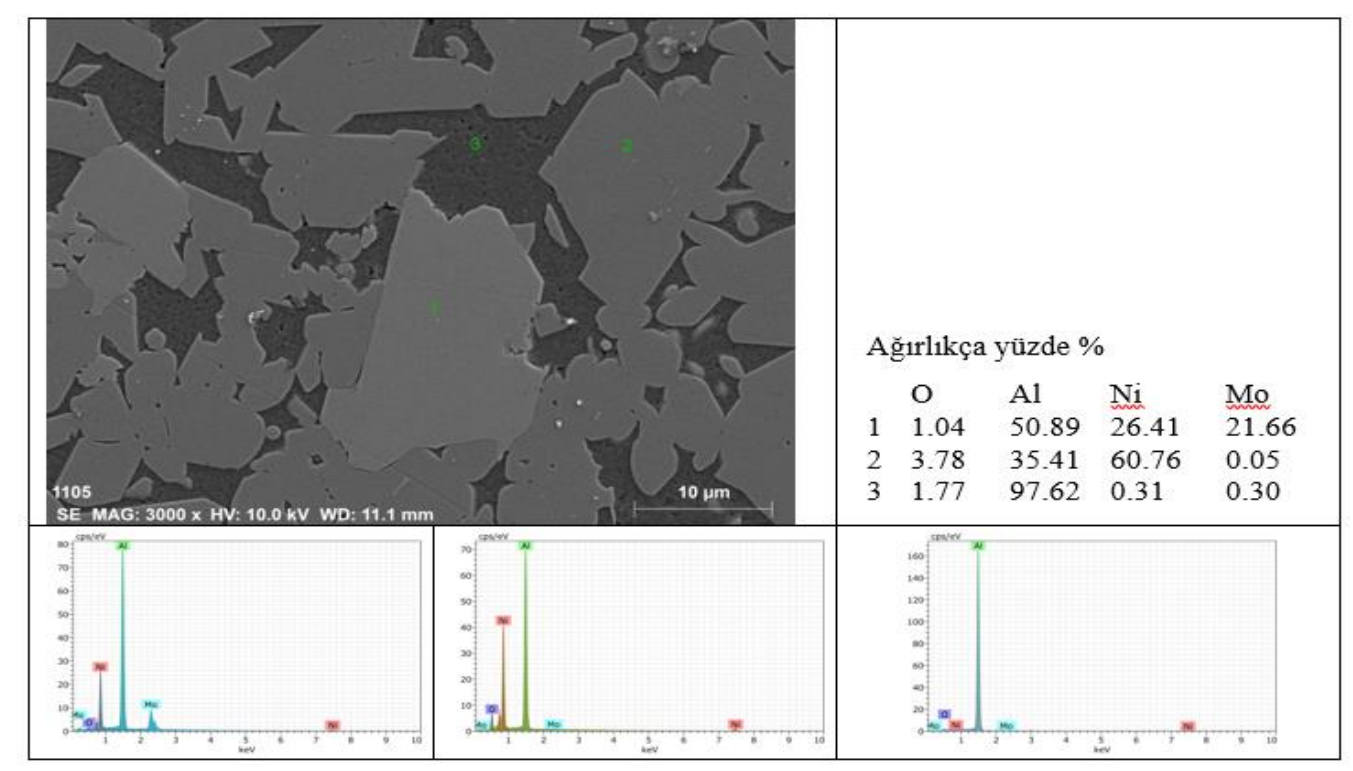

Şekil 4. A malzemesine ait SEM görüntüsü ve farklı bölgelerin nokta EDS analizleri ( SEM image of sample A and point EDS analysis of different regions ) 
NiAl partiküllerinin üzerinde bulunan Mo içeren faz bölgesinde yapılan çizgi EDS analizi Şekil 5 ' te verilmiştir. Bu incelemede de görüldügüü üzere alt faz $\mathrm{Ni}$ ve $\mathrm{Al}$ içermektedir. Üzerinde oluşan fazda ise molibden oranı hızla artmakta $\mathrm{Ni}$ oranı ise buna orantılı olarak düşmektedir. Bunların yanı sıra Al miktarında da bir miktar düşüş görülmüştür. Sonuç itibariyle XRD analizlerinde de belirtildiği gibi Al' ca zengin Al-Ni-Mo üçlü fazı oluştuğu tespit edilmiştir.
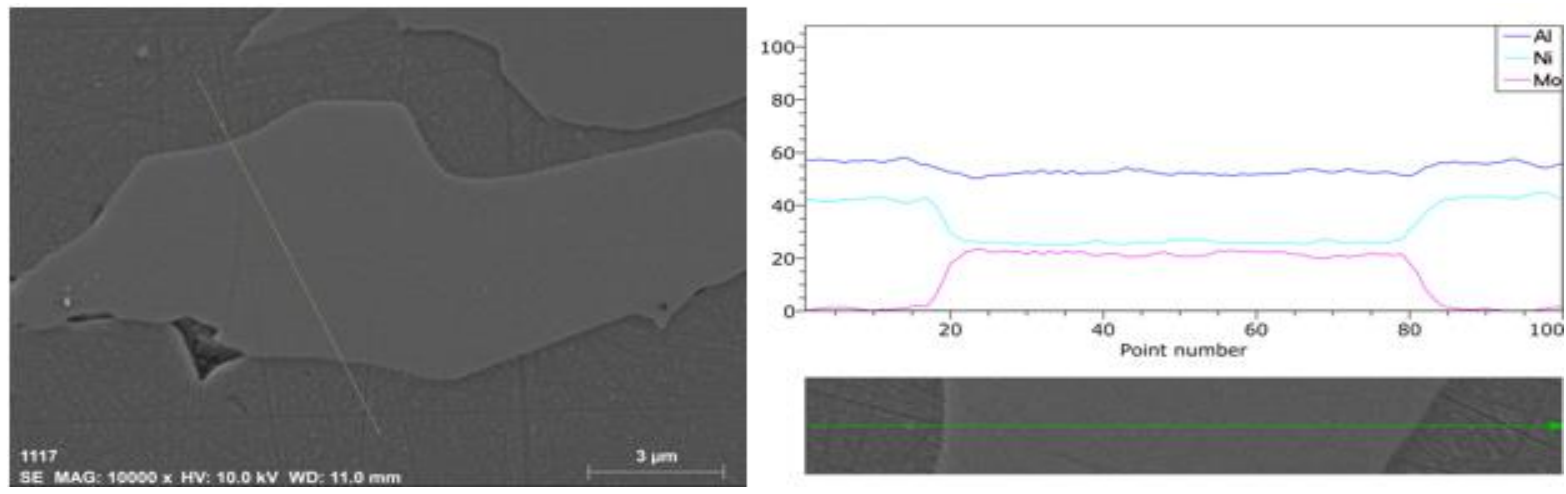

Şekil 5. C numunesi mikroyapı görüntüsü ve çizgi EDS analizi (Microstructure image and line EDS analysis of C sample )

\subsection{XRD İncelemeleri}

Kompozitler üzerinde yapılan XRD analiz sonuçları toplu halde Şekil 6' da verilmiştir. Genel olarak incelendiğinde her üç tür kompozitte de benzer piklerin oluştuğu görülmektedir. Oluşan paternlerden keskin Bragg pikleri $\mathrm{Al}, \mathrm{NiAl}, \mathrm{Al}_{3} \mathrm{Ni}_{2}, \mathrm{Al}_{3} \mathrm{Ni}$ ve $\mathrm{Al}-\mathrm{Ni}-\mathrm{Mo}$ üçlü fazlarından oluşmaktadır.

Gözlemlenen keskin pikler dişında küçük birçok pik de görülmektedir. Bunların birçoğu belirtilen fazların oluşturduğu keskin piklerin devamı niteliğindedir. $\mathrm{Bu}$ fazlar dışında literatür incelemelerinde Ni, Al ve Mo arasında çeşitli fazların oluştuğu belirtilmiştir [9]. Elde edilen patern üzerinde tanımlanamayan bazı küçük piklerin bu alaşım kombinasyonuna bağlı olarak da oluşabileceği düşünülmektedir.

Oluşan fazlar değerlendiğinde, NiAl partiküllerinin bir kısmının Al matris ile etkileşime geçerek $\mathrm{Al}_{3} \mathrm{Ni}$ ve $\mathrm{Al}_{3} \mathrm{Ni}_{2}$ gibi $\mathrm{Al}$ ' ca zengin fazlar oluşturduğu görülmektedir. Üretimin $800{ }^{\circ} \mathrm{C}^{\prime} \mathrm{de}$ gerçekleştirildiği düşünülürse bu dönüşümlerin oluşması normaldir. Zaten bu durum önceden beklendiği için partiküllere Mo ilave edilmiş ve üretim süresi kısa tutulmuştur. Bunların sonucunda mikroyapı incelemelerini de göz ününe aldığımızda büyük miktarda çözünmelerin oluşmadığ1 belirlenmiştir. 


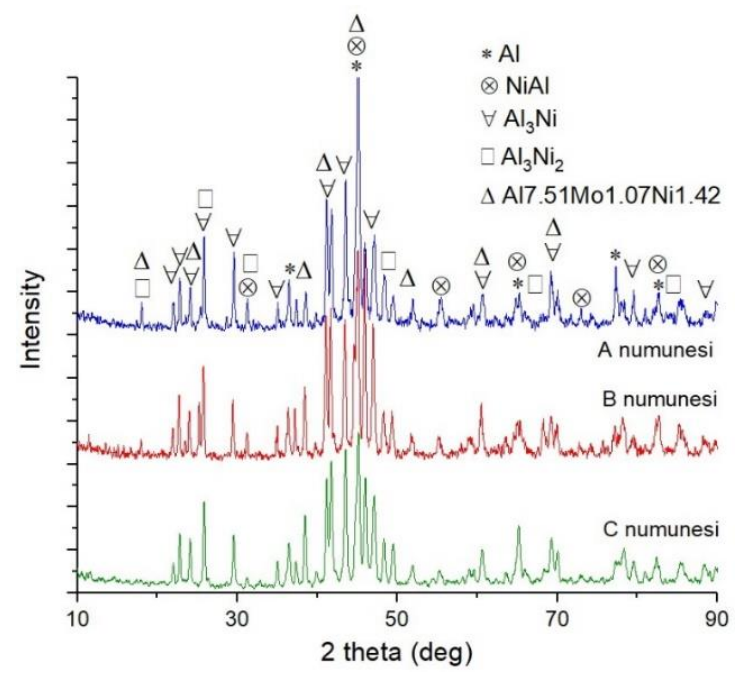

Şekil 6. Kompozit malzemelere ait XRD analizi ( XRD analysis of composite materials )

\subsection{Yoğunluk Ölçüm Sonuçları}

Kompozitlerin yoğunluk değerleri sırası ile A malzemesi için $3.583 \mathrm{gr} / \mathrm{cm}^{3}$, B için $3.293 \mathrm{gr} /$ $\mathrm{cm}^{3}$ ve C için ise $3.649 \mathrm{gr} / \mathrm{cm}^{3}$ olarak ölçülmüştür. Bu yoğunluk değerlerine bakıldığında hacimce ilave edilen partikül oranı benzer olmasına rağmen değerlerde farklılıklar gözlemlenmiştir. Ayrıca teorik olarak yoğunluk değerinin $3.9 \mathrm{gr} / \mathrm{cm}^{3}$ civarında olması beklenmektedir. Bu durum partikül boyutunun paketlenebilirliğe etkisine ve mikroyapı incelemelerinde de farkedildiği şekilde kompozitin tüm kesitinde homojenlik göstermemesine bağlanmıştır. Stokiyometrik olmayan NiAl' in yoğunluğu Al' ca zengin olan bölgelerde $5.3 \mathrm{~g} / \mathrm{cm}^{3}$ e kadar düşebilmektedir [10].

\subsection{Korozyon Testi Sonuçları}

Potansiyodinamik polarizasyon deneyi anodik ve katodik bölgelerde tarama ayrık olarak yapılmış ve birleştirilmiş hali Şekil 7' de verilmiştir.



Şekil 7. Potansiyodinamik polarizasyon deney grafikleri ( Potentiodynamic polarization tests plots )

Şekil 7' de verilen grafik incelendiğinde anodik bölgedeki verilen gerilim başına çekilen akım değerlendirildiğinde $\mathrm{A}$ ve $\mathrm{B}$ numuneleri benzer davranışlar sergilediği $\mathrm{C}$ numunesinin ise diğerlerine göre daha pasif davrandığı grafik eğrilerinden anlaşılmaktadır. Katodik bölgede ise oluşan grafikler birbirlerine oldukça yakın oluşmuşlardır. Bunların dışında grafiklerde herhangi bir aktifleşme yada pasifleşme bölgesi oluşmamıştır. 
Grafikteki korozyon potansiyeli ( $\left.\mathrm{E}_{\mathrm{corr}}\right)$ değerleri $15 \mathrm{dk}$ ' lık açı devre (OC) deney sonucu edinilen değerlerdir. Grafikler bu yönden değerlendirildiğinde B malzemesi en agrasif A malzemesinde ise korozyon oranı en düşüktür. Bu sonuç anodik bölgedeki oluşum ile de tutarlılık göstermektedir.

Grafikte genel bir tafel ekstrapolasyonu oluşturulamadığından dolayı sadece katodik bölgedeki datalar kullanılarak akım yoğunluğu $\left(i_{\text {corr }}\right)$ değerleri belirlenmiştir. Belirlenen $i_{\text {corr }}$ değerleri ve buna bağlı olarak Faraday kanunu (ASTM G-102) ile hesaplanan korozyon oranlar1 Tablo 2' de verilmiştir.

Tablo 2. Potansiyodinamik polarizasyon deneyleri sonrasında belirlenen korozyon yoğunluğu ( $\mathrm{i}_{\text {corr }}$ ) ve korozyon oranı değerleri ( Corrosion density $\left(\mathrm{i}_{\text {corr }}\right.$ ) and corrosion rate values determined after potentiodynamic polarization tests )

Korozyon yoğunluğu $\left(\mu \mathrm{A} / \mathrm{cm}^{2}\right)$

Korozyon oranı (mm / yıl)

\begin{tabular}{lcc}
\hline $\mathbf{A}$ & 6.51 & 0.22 \\
$\mathbf{B}$ & 14.30 & 0.48 \\
$\mathbf{C}$ & 11.00 & 0.37
\end{tabular}

Tablo 2' de verilen korozyon değerlerine bakıldığında $i_{\text {corr }}$ değeri ve buna bağlı olarak korozyon oranı A numunesinde en düşük çıkmıştır. En yüksek korozyon oranı B malzemesinde çıkmakla birlikte C'ye yakın değerler tespit edilmiştir. Bu kullanılan $i_{\text {corr }}$ değerleri açık devre (OC) testinden edinilen değerlerin oluşturduğu eksen ve katodik bölgenin ekstrapolasyonu ile elde edildiğinden dolayı OC değerleri ile de benzerlik göstermektedir. $\mathrm{Bu}$ edinilen değerler deney numuneleri arasındaki nitel farklılıkları vermekle birlikte gerçekçi sonuçlar sunmayacağı bilinmektedir. Bu amaçla benzer tuzluluk ortamında daldırma korozyon deneyleri gerçekleştirilmiş ve mm / y1l cinsinden hesaplanan korozyon oranları Şekil 8'de verilmiştir.

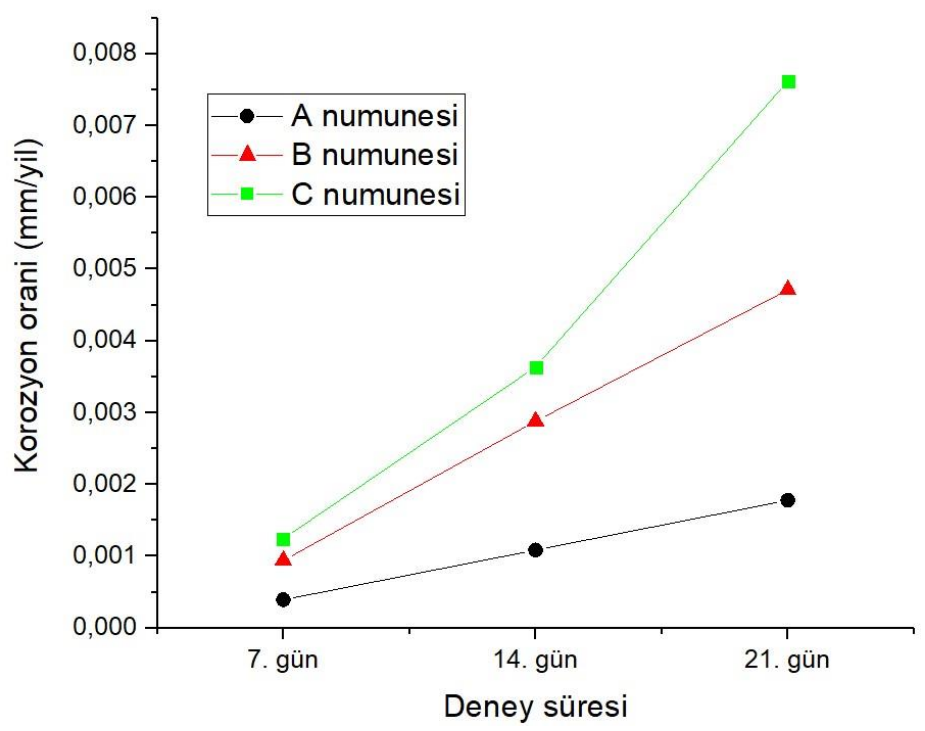

Şekil 8. \% $3.5 \mathrm{NaCl}$ ortamında daldırma korozyonu test grafiği ( Immersion corrosion test chart in $\% 3.5 \mathrm{NaCl}$ solution )

Şekil 8'e baktığımızda ilk 7 günün sonunda özellikle B ve C numunelerinde kütle kayıplarının birbirine yakın seyrettiği görülmüş fakat ilk periyottan sonra, NiAl partikül boyutunun küçültülmesinin önemli ölçüde korozyon direncinin arttırdığı ve sonuç olarak en fazla kütle kaybının $\mathrm{C}$ numunesinde gerçekleştiği gözlemlenmiştir. Yapılan çalışmalar daha büyük boyutlu 
partikül kullanıldığında ve korozif çözeltiye maruz kalma süresi arttıkça korozyon dayanımın düştüğü ve oyuklanma potansiyelinin arttığını rapor etmiştir [5, 11].

Potansiyodinamik polarizasyon deneyinde ince bir tabakada test yapılırken daha gerçekçi olan daldırma korozyonunda kayıplar çok daha büyük olmaktadır. Bu durumda yüksek oranda takviye fazı içeren deney numunesinde matrisin korozyona uğraması ile tutucu özelliğini yitirdiği ve bu sebeple malzemede büyük çukurcukların oluştuğu gözlemlenmiştir. Yoğunluk ölçüm sonuçlarını incelediğimizde en düşük yoğunluk $3.583 \mathrm{gr} / \mathrm{cm}^{3}$ ile A numunesinde tespit edilmiştir. Bu sonuçlar bize düşen tane boyutunun porozite miktarını arttırdığını göstermektedir ki buna rağmen korozyon dayanımı artmaktadır. Elde edilen sonuçlara göre üretilen kompozitlerin korozyon davranışlarında tane boyutu ve arayüzeyde oluşan intermetalikler poroziteden daha ziyade rol oynamaktadır.

Literatürde de belirtildiği gibi Al ve seramik partiküller arasındaki reaksiyonun bir sonucu olarak oluşan intermetaliklerin, kompozitler içindeki matris kanallarının sürekliliğinin kesintiye uğraması nedeniyle kompozitlerin korozyon direncine yararlı bir etkisi olduğunu göstermiş̧tir [5]. Bilindiği üzere tane boyutu küçüldüğünde yüzey alanı artan takviye elemanı ile matris malzemesinin reaksiyon hızı artmaktadır. Bu durum yapılan XRD analizlerinde de görülmektedir. Sonuç olarak Şekil 9' da incelenen kompozit malzemelere ait yüzey fotoğraflarına baktığımızda korozyon kaynaklı yüzey deformasyonu özellikle B ve C numunelerinde oyuklanma şeklinde görülmekte bu durumda oldukça büyük kütle kayıplarına yol açmaktadır. A numunesinde ise daha düşük kütle kayıpları olmasının yanında yüzeyde daha küçük oyuklanmalar görülmektedir.
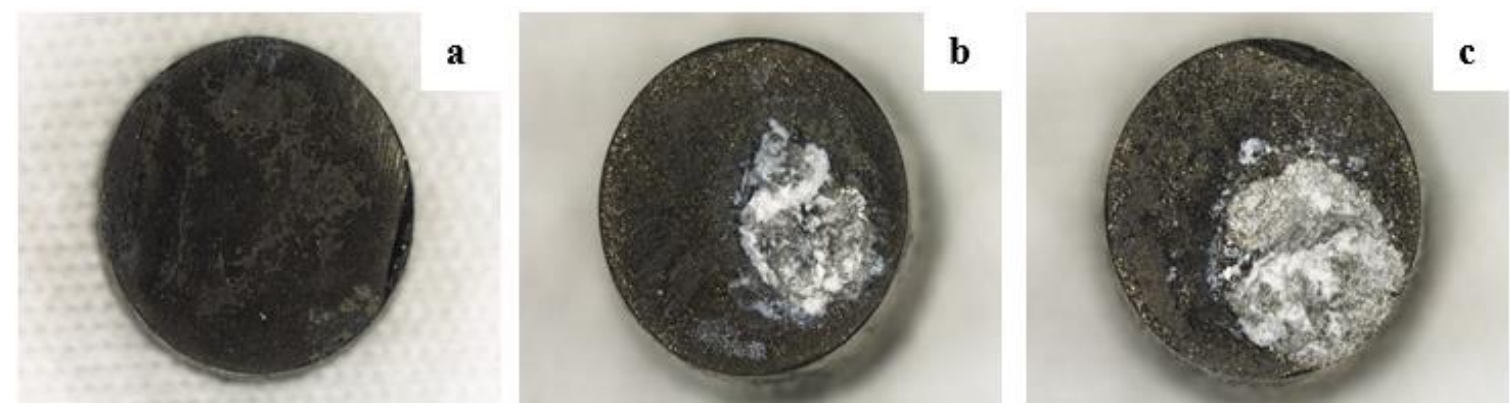

Şekil 9. Daldırma korozyon testi sonrası yüzeyden alınan makro fotoğraflar ( Macro-photos was taken from the surface after immersion corrosion test )

Yan kesit fotoğraflarına baktığımızda (Şekil 10) ise korozyonun matris boyunca gerçekleştiği takviye ve oluşan intermetaliklerin matris sürekliliğini bozarak korozyon ürünlerine karşı bariyer görevi yaptığı görülmektedir [5]. Bunun yanında takviye elemanı ile matris arasında galvanik ikili oluştuğu ve matrisin korozyonunun hızlandığı düşünülmektedir. Bunun sonucunda da matris ile bağlantısı kesilen takviyelerinde kompozit yapıdan ayrılarak korozyonun hızlanmasında etkili olduğu tespit edilmiştir.
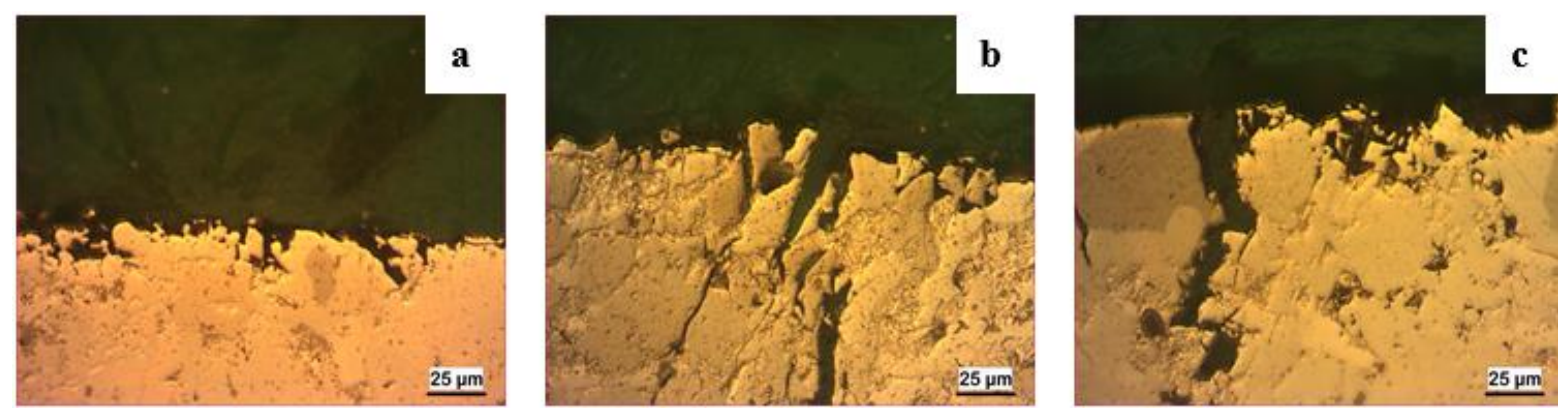

Şekil 10. Daldırma korozyon testi sonrası yan kesitten alınan mikro fotoğraflar ( Micro-photos was taken from the cross-section after the immersion corrosion test) 


\section{SONUÇLAR (CONCLUSIONS)}

$\mathrm{Bu}$ çalışmada yüksek oranda (\% 40) NiAl partikül takviyeli Al matrisli kompozitler basınçlı infiltrasyon yöntemi ile başarılı bir şekilde üretilmiştir. Üretim aşamasında partikül boyutu değiştirilerek bu faktörün kompozitin özelliklerine etkisi incelenmiştir.

Korozyon deneyleri sonrasında en küçük partikül boyutuna sahip kompozit en yüksek korozyon direnci gösteren malzeme olmuştur. Diğer ikisi ise potansiyodinamik polarizasyon deneyinde yakın değerler göstermekle birlikte daldırma korozyonunda en yüksek ağırlık kaybına en kaba partiküllü C kompoziti uğramıştır.

Sonuç itibari ile üretilen kompozitler genel manada kıyaslandığında her iki korozyon metodunda da en yüksek korozyon dayanımı 45-63 $\mu \mathrm{m}$ aralığında NiAl partikül içeren A kodlu kompozitte elde edilmiştir.

\section{TEŞEKKÜR (ACKNOWLEDGMENT)}

$\mathrm{Bu}$ çalışma Karabük Üniversitesi Bilimsel Araştırma Projeleri tarafından desteklenmiştir. (Proje no: KBUBAP-18-YL-149).

\section{KAYNAKLAR (REFERENCES)}

1. A.Lekatou, A.E. Karantzalis, A. Evangelou, V. Gousia, G. Kaptay, Z. Gácsi, P. Baumli and A. Simon, Aluminium reinforced by WC and TiC nanoparticles (ex-situ) and aluminide particles (in-situ), Microstructure, wear and corrosion behaviour, Materials and Design, 65: 1121-1135 (2015).

2. H. Çuğ and M. E. E. Erhaima, Effect of Mn and Zr Addition on Microstructure, Wear and Corrosion Behavior of Ti-6Al-4V Composite Biomaterials Produced by Powder Metallurgy, Manufacturing Technologies and Applications, 2 (2): 41-48 (2021).

3. S. Candan, An investigation on corrosion behaviour of pressure infiltrated $\mathrm{Al}-\mathrm{Mg}$ alloy/SiCp composites, Corrosion Science, 51: 1392-1398 (2009).

4. K. H. W. Seah, M. Krishna, V. T. Vijayalakshmi and J. Uchil, Corrosion behaviour of garnet particulate reinforced LM13 Al alloy MMCs, Corrosion Science, 44: 917-925 (2002).

5. S. Candan, Effect of $\mathrm{SiC}$ particle size on corrosion behavior of pressure infiltrated $\mathrm{Al}$ matrix composites in a $\mathrm{NaCl}$ solution, Mater Letters, 58(27-28): 3601-3605 (2004).

6. ASTM G102-89, Standard practice for calculation of corrosion rates and related information from electrochemical measurements, ASTM International, 2004.

7. ASTM G 31-72, Standard practice for laboratory immersion corrosion testing of metals, ASTM International, 1990.

8. M. Conserva, G. Donzelli and R. Trippodo, Aluminum and Its Applications, Edimet, Brescia, 1992.

9. B. Grushko, S. Mi, J.G. Highfield, A study of the Al-rich region of the Al-Ni-Mo alloy system, Journal of Alloys and Compounds, 334 (1-2): 187-191 (2002).

10.A. Taylor and N. Doyle, Further studies on the nickel-aluminium system. I. $\beta \mathrm{NiAl}$ and $\delta$-Ni2Al3 phase fields, Journal of Applied Crystallography, 5(3): 201-209 (1972).

11.H. M. Zakaria, Microstructural and corrosion behavior of $\mathrm{Al} / \mathrm{SiC}$ metal matrix composites, Ain Shams Engineering Journal, 5(3): 831-838 (2014). 